\title{
Predictors for second-stage posterior direct decompression after lateral lumbar interbody fusion: a review of five hundred fifty-seven patients in the past five years
}

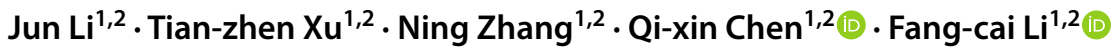

Received: 15 December 2021 / Accepted: 16 January 2022 / Published online: 7 February 2022

(c) The Author(s) 2022

\begin{abstract}
Purpose To analyze the predictors for second-stage posterior direct decompression (PDD) after lateral lumbar interbody fusion (LLIF) procedure.

Methods We studied patients who underwent LLIF for degenerative lumbar spinal stenosis in the last five years, from July 2016 to June 2021. All surgical levels were grouped according to Schizas' central canal stenosis (CCS) classification, Pathria's facet joint degeneration (FJD) classification, Bartynski's lateral recess stenosis (LRS) classification, and Lee's foraminal stenosis (FS) classification. Second-stage PDD rates of each subgroup and their annual change were analyzed. Evaluation of risk factors associated with PDD was investigated.

Results A total of 901 segments from 557 patients were included. The overall PDD rate was $29.97 \%$. An overall PDD rate of $75.21 \%$ for grade D CCS, $29.74 \%$ for grade C CCS, $41.67 \%$ for grade 3 FJD, $37.61 \%$ for grade 3 LRS, and $40.70 \%$ for grade 3 FS was shown. While there was a continuous decline in annual PDD rate in the past four years, the annual PDD rate for grade D remained at very high levels. Logistic regression analysis had shown grade D CCS as the utmost risk factor for PDD $(\mathrm{OR}=17.77)$. And grade $3 \mathrm{LRS}(\mathrm{OR}=4.63)$, grade $3 \mathrm{FS}(\mathrm{OR}=2.42)$, grade $\mathrm{C} C \mathrm{CS}(\mathrm{OR}=2.41)$, and grade 3 FJD $(\mathrm{OR}=2.04)$ were also moderately correlated with PDD, which meant they only moderately increased the risk of PDD. Conclusion Extreme severe lumbar CCS (grade D) is the greatest determinant to perform the second-stage PDD procedure after LLIF.
\end{abstract}

Keywords Lateral lumbar interbody fusion · Indirect decompression · Lumbar spinal stenosis $\cdot$ Central canal $\cdot$ Facet joint $\cdot$ Lateral recess · Foramen

\section{Introduction}

The minimally invasive lateral lumbar interbody fusion (LLIF) is an indirect decompression technique, resulting in a lower approach-related morbidity in comparison to

Jun Li and Tian-zhen Xu contributed equally to this work.

Qi-xin Chen

zrcqx@zju.edu.cn

$\triangle$ Fang-cai Li

2505004@zju.edu.cn

1 Department of Orthopedics, The Second Affiliated Hospital, School of Medicine, Zhejiang University, No.88 Jiefang Road, Hangzhou 310009, Zhejiang Province, China

2 Department of Orthopedics, Zhuji People's Hospital of Zhejiang Province, Shaoxing, Zhejiang Province, China traditional open decompression techniques [1, 2]. Radiographic decompression results reveal LLIF to be significantly worse when compared to minimally invasive transforaminal lumbar interbody fusion (MIS-TLIF) [3], let alone conventional TLIF or posterior lumbar interbody fusion. Although plenty of studies had previously shown that the clinical outcome of LLIF for LSS is comparable to MISTLIF and TLIF [4-9], a surgical indication of LLIF for LSS varied amongst different surgeons. It is noted that there are still doubts or hesitance in performing the LLIF procedures on patients with severe lumbar degenerative diseases.

According to current research, the possible risk factor of failed indirect decompression includes severe central canal stenosis (CCS) [10-12], bony lateral recess stenosis (LRS) [13], uncontained disc herniation, locked facet, severe hypertrophy of ligamentum flavum [14], cage subsidence $[15,16]$, and osteoporosis [17]. In clinical settings, due 
to poorly recognized indications to perform PDD, nor the definition regarding indirect decompression failure, additional PDD rate after LLIF showed variation across different studies with a range of $0 \sim 72 \%[13,15,16,18-23]$. Many of those PDD were likely unnecessary. According to these studies, we should include the risk factors for PDD in further studies to determine a clear indication of LLIF for lumbar spinal stenosis (LSS).

In this study, we retrospectively studied patients who underwent LLIF for LSS over the last five years in our institution, where an annual change of PDD rate data was collected. PDD rates obtained were further compared between subgroups according to different radiographic classifications. We then analyzed the risk factors for PDD through univariate and multivariable logistic regression model, which helped us better acknowledge the indication of LLIF for LSS.

\section{Materials and methods}

\section{Patients}

In this retrospective study, patients with the main diagnosis of degenerative LSS had undergone a procedure performed by our surgical group between July 2016 and June 2021 . The procedure involved was crenel lateral lumbar interbody fusion (CLIF, SANYOU, China), which is a modified extreme lateral interbody fusion technique (XLIF). Patients who suffered from significant lumbar scoliosis $\left(\mathrm{Cobb} \geq 20^{\circ}\right.$ ), grade two spondylolisthesis, and lumbar fracture or had undergone prior lumbar surgery were excluded from this study.

\section{Evaluation}

Demographic data were collected. The annual PDD rate, staged surgery rate, average hospital stays, and average cage height of consecutive five years, namely from July 2016 to June 2017, July 2017 to June 2018, July 2018 to June 2019, July 2019 to June 2020, and July 2020 to June 2021, were collected. All these segments were then further grouped according to Schizas' CCS classification [24], Bartynski's LRS classification [25] and Lee's foraminal stenosis (FS) classification [26] on MRI, and Pathria's facet joint degeneration (FJD) classification [27] on CT (Fig. 1). CCS were graded as A (mild), B (moderate), C (severe), and D (extremely severe). LRS, FS, and FJD were graded as 0 (normal), 1 (mild), 2 (moderate), and 3 (severe). FJD, LRS, and FS should have been evaluated on both sides. However, we had only accounted for the severe side. The radiographic measurements were performed by board-certified spine surgery fellows (T.X and J.L.). PDD rate of each subgroup and their annual change were further compared.

\section{Surgical techniques}

The CLIF technique is a modified technique of XLIF, aimed to minimize approach-related complications. For patients with staged surgery, posterior instrumentation with/without PDD is performed one week after the first stage. When there is an inadequate resolution of stenotic symptoms or radicular leg pain, and a positive straight leg raise test or femoral nerve stretch test after CLIF, PDD will be performed. The indication of PDD may vary amongst different attending surgeons, where views on the matter may have slightly changed in the past five years.

\section{Statistics}

Descriptive data are represented as means \pm standard deviation (SD). The pre-operative variables can contribute to PDD including age, sex, BMI, diagnosis, surgical segments, cage height, and radiographic parameters, which were first analyzed by the univariate correlation. Categorical variables were presented as numbers and percentages (\%). A chisquared test was used in the analysis of categorical variables. Variables that were significantly associated with PDD in the univariate analysis were entered into a multivariable logistic regression model to identify the independent pre-operative radiologic factors predictive of PDD. In multivariable logistic regression model, we adjusted for age, sex, BMI, cage height, and number of surgical segments and whether there was spondylolisthesis as contributors. To further explore the effect of surgical experience on results, a subgroup analysis was conducted according to different years. A two-sided $P$ value $<0.05$ was deemed statistically significant. All statistical analyses were performed using $\mathrm{R}$ (version 4.1.0; $\mathrm{R}$ Development Core Team).

\section{Results}

A total of 901 segments from 557 patients who underwent LLIF were studied, which includes one segment of L1/2, 85 segments of L2/3, 306 segments of L3/4, and 509 segments of $L 4 / 5$. The mean age of patients was $65.22 \pm 7.64$ years, and the mean BMI was $24.66 \pm 3.18 \mathrm{~kg} / \mathrm{m}^{2}$. The patient sample group consists of 260 males and 297 females. The mean cage height was $12.97 \pm 1.44 \mathrm{~mm}$. One-level fusion was performed in 278 patients, two-level fusion in 214 patients, and three-level fusion in 65 patients. Spondylolisthesis was observed at $31.85 \%$ (287/901) of all surgical segments.

Table 1 displays a trend, where annual surgical procedures and surgical segments were observed to have been 

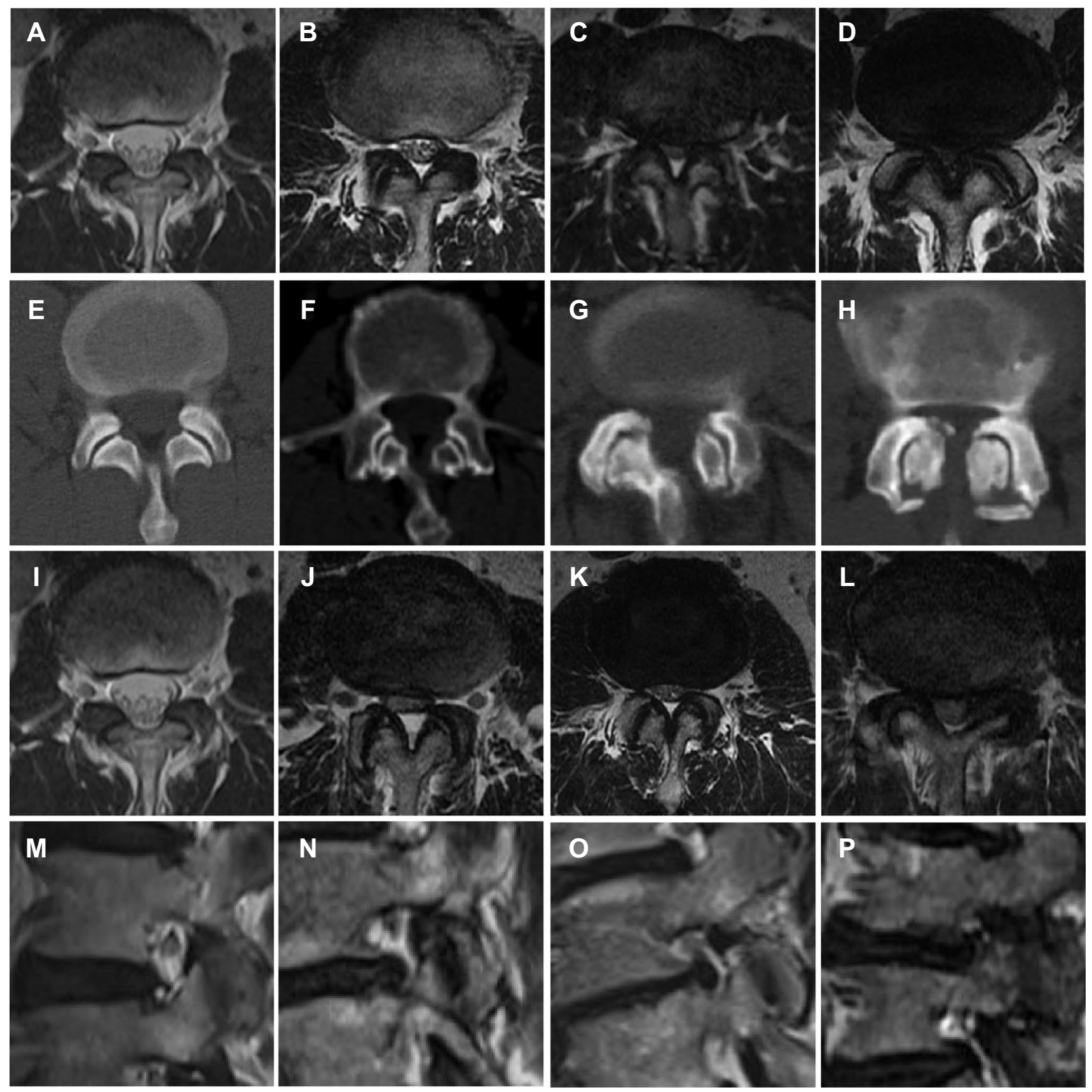

Fig. 1 Typical images illustrate radiographic classifications. Schizas' central canal stenosis (CCS) classification (a-d), a Grade A; b Grade B; c Grade C; d Grade D. Pathria's facet joint degeneration (FJD) classification (e-h), e Grade 0; f Grade 1; g Grade 2; h Grade 3. Bar-

tynski's lateral recess stenosis (LRS) classification (i-l), $\mathbf{i}$ Grade $0 ; \mathbf{j}$ Grade 1; k Grade 2; $\mathbf{l}$ Grade 3. Lee's foraminal stenosis (FS) classification (m-p), m Grade 0; $\mathbf{n}$ Grade 1; o Grade 2; p Grade 3

increasing in the last five years, whereas staged surgery rates were seen decreasing. This is attributed to our improvement in understanding indications for LLIF in LSS. Due to fewer staged surgical procedures, average hospital stays were continuously decreasing in the past five years. The overall PDD rate is $29.97 \%$ (270/901). The annual PDD rate observed a

continuous decline in the past four years, and most recently showed a rate of $23.13 \%$ in the last year.

A significant trend observed for CCS, FJD, LRS, and FS is where there are more severe grading classifications, the higher the total PDD rate (Table 2). However, there were no significant differences in the proportion of four grades in 
Table 1 Annual change of parameters related with LLIF surgery for LSS

\begin{tabular}{lllllllll}
\hline Year & Surgeries $(n)$ & $\begin{array}{l}\text { Staged } \\
\text { surgery }\end{array}$ & $\begin{array}{l}\text { Staged surgery } \\
\text { rate }(\%)\end{array}$ & Segments $(n)$ & PDD $(n)$ & PDD rate $(\%)$ & Hospital stay (days) & Cage height $(m m)$ \\
\hline $2016-2017$ & 39 & 32 & $82.05(32 / 39)$ & 65 & 15 & $23.78(15 / 65)$ & $18.21 \pm 4.45$ & $13.40 \pm 1.37$ \\
$2017-2018$ & 99 & 89 & $89.90(89 / 89)$ & 145 & 62 & $42.76(62 / 145)$ & $18.45 \pm 6.07$ & $13.45 \pm 1.20$ \\
$2018-2019$ & 120 & 97 & $80.83(97 / 120)$ & 193 & 67 & $34.72(67 / 193)$ & $17.61 \pm 6.34$ & $13.43 \pm 1.26$ \\
$2019-2020$ & 131 & 79 & $60.31(79 / 131)$ & 204 & 58 & $28.43(58 / 204)$ & $13.84 \pm 5.60$ & $12.95 \pm 1.41$ \\
$2020-2021$ & 168 & 91 & $54.17(91 / 168)$ & 294 & 68 & $23.13(68 / 294)$ & $12.04 \pm 5.00$ & $12.34 \pm 1.46$ \\
\hline
\end{tabular}

LLIF lateral lumbar interbody fusion; $L S S$ lumbar spinal stenosis; $P D D$ posterior direct decompression

Table 2 Annual change of PDD rate according to radiographic classifications

\begin{tabular}{|c|c|c|c|c|c|c|}
\hline & Total PDD rate $(\%)$ & $\begin{array}{l}2016-2017 \\
\text { PDD rate }(\%)\end{array}$ & $\begin{array}{l}2017-2018 \\
\text { PDD rate (\%) }\end{array}$ & $\begin{array}{l}2018-2019 \\
\text { PDD rate }(\%)\end{array}$ & $\begin{array}{l}2019-2020 \\
\text { PDD rate }(\%)\end{array}$ & $\begin{array}{l}2020-2021 \\
\text { PDD rate }(\%)\end{array}$ \\
\hline \multicolumn{7}{|l|}{ CCS grade } \\
\hline A & $16.67 \%(10 / 60)$ & $8.33 \%(1 / 12)$ & $14.29 \%(1 / 7)$ & $28.57 \%(4 / 14)$ & $30 \%(3 / 10)$ & $5.88 \%(1 / 17)$ \\
\hline B & $14.65 \%(40 / 273)$ & $20 \%(5 / 25)$ & $21.62 \%(8 / 37)$ & $11.11 \%(6 / 54)$ & $7.41 \%(4 / 54)$ & $16.50 \%(17 / 103)$ \\
\hline $\mathrm{C}$ & $29.74 \%(135 / 454)$ & $25 \%(6 / 24)$ & $46.75 \%(36 / 77)$ & $37.25 \%(38 / 102)$ & $27.43 \%(31 / 113)$ & $17.39 \%(24 / 138)$ \\
\hline $\mathrm{D}$ & $74.56 \%(85 / 114)$ & $75 \%(3 / 4)$ & $70.83 \%(17 / 24)$ & $82.61 \%(19 / 23)$ & $74.07 \%(20 / 27)$ & $72.22 \%(26 / 36)$ \\
\hline \multicolumn{7}{|l|}{ FJD grade } \\
\hline 0 & $13.24 \%(9 / 68)$ & $1.25 \%(1 / 8)$ & $14.29 \%(2 / 14)$ & $21.43 \%(3 / 14)$ & $7.14 \%(1 / 14)$ & $11.11 \%(2 / 18)$ \\
\hline 1 & $28.25 \%(102 / 361)$ & $22.22 \%(8 / 36)$ & $35.38 \%(23 / 65)$ & $30 \%(24 / 80)$ & $26.09 \%(18 / 69)$ & $26.13 \%(29 / 111)$ \\
\hline 2 & $30.59 \%(104 / 340)$ & $30.77 \%(4 / 13)$ & $50 \%(22 / 44)$ & $40 \%(28 / 70)$ & $29.21 \%(26 / 89)$ & $19.35 \%(24 / 124)$ \\
\hline 3 & $41.67 \%(55 / 132)$ & $25 \%(2 / 8)$ & $68.18 \%(15 / 22)$ & $41.38 \%(12 / 29)$ & $40.63 \%(13 / 32)$ & $31.71 \%(13 / 41)$ \\
\hline \multicolumn{7}{|l|}{ LRS grade } \\
\hline 0 & $10 \%(2 / 20)$ & $0 \%(0 / 4)$ & $0 \%(0 / 3)$ & $16.67 \%(1 / 6)$ & $16.67 \%(1 / 6)$ & $0 \%(0 / 5)$ \\
\hline 1 & $12.36 \%(11 / 89)$ & $22.22 \%(2 / 9)$ & $18.18 \%(2 / 11)$ & $5.89 \%(1 / 17)$ & $14.29 \%(3 / 21)$ & $11.11 \%(3 / 27)$ \\
\hline 2 & $20.97 \%(52 / 248)$ & $10.53 \%(2 / 19)$ & $26.92 \%(7 / 26)$ & $27.78 \%(15 / 54)$ & $19.35 \%(12 / 62)$ & $18.60 \%(16 / 86)$ \\
\hline 3 & $37.61 \%(205 / 545)$ & $33.33 \%(11 / 33)$ & $50.48 \%(53 / 105)$ & $43.10 \%(50 / 116)$ & $36.52 \%(42 / 115)$ & $27.84 \%(49 / 176)$ \\
\hline \multicolumn{7}{|l|}{ FS grade } \\
\hline 0 & $17.06 \%(29 / 170)$ & $23.53 \%(4 / 17)$ & $21.05 \%(4 / 19)$ & $20 \%(9 / 45)$ & $17.50 \%(7 / 40)$ & $10.20 \%(5 / 49)$ \\
\hline 1 & $26.33 \%(79 / 300)$ & $17.65 \%(3 / 17)$ & $18.18 \%(19 / 52)$ & $34.62 \%(27 / 78)$ & $18.03 \%(11 / 61)$ & $20.65 \%(19 / 92)$ \\
\hline 2 & $35.52 \%(92 / 259)$ & $22.22 \%(4 / 18)$ & $46.15 \%(18 / 39)$ & $43.40 \%(23 / 53)$ & $35.71 \%(20 / 56)$ & $29.03 \%(27 / 93)$ \\
\hline 3 & $40.70 \%(70 / 172)$ & $30.77 \%(4 / 13)$ & $60 \%(21 / 35)$ & $47.06 \%(8 / 17)$ & $42.55 \%(20 / 47)$ & $28.33 \%(17 / 60)$ \\
\hline \multicolumn{7}{|l|}{ Diagnosis } \\
\hline LSS & $28.62 \%(176 / 615)$ & $27.5 \%(11 / 40)$ & $33.33 \%(27 / 81)$ & $35.88 \%(47 / 131)$ & $30.99 \%(44 / 142)$ & $21.36 \%(47 / 220)$ \\
\hline $\begin{array}{l}\text { LSS/spon- } \\
\text { dylolisthe- } \\
\text { sis }\end{array}$ & $33.94 \%(94 / 277)$ & $16 \%(4 / 25)$ & $54.69 \%(35 / 64)$ & $32.26 \%(20 / 62)$ & $22.58 \%(14 / 62)$ & $28.38 \%(21 / 74)$ \\
\hline
\end{tabular}

CCS central canal stenosis; FJD facet joint degeneration; LRS lateral recess stenosis; FS foraminal stenosis; LSS lumbar spinal stenosis; PDD posterior direct decompression

those parameters in the past 5 years (Fig. 2). CCS grade $\mathrm{C}$ or D segments account for $63.04 \%$ (568/901) of all segments. FJD grade 3 segments account for $14.65 \%$ (132/901). LRS grade 3 segments account for $60.49 \%$ (545/901). FS grade 3 segments account for $19.09 \%$ (172/901).

The annual PDD rate for CCS grade $\mathrm{C}$ was seen to have increased in the second year (Table 2 and Fig. 3a). However, it then continued to decline to $17.39 \%$ in the most recent year, which was not significantly different from that of grade B $(p=1.00)$. The annual PDD rate for grade D remained at very high levels $(70.88 \sim 82.61 \%)$ in the past five years of this study (Table 2 and Fig. 3a). We observed that the overall PDD rate for grade D is significantly larger than that of grade 3 FJD, LRS, and FS (Table 2). The overall PDD rate for grade 3 FJD, LRS, and FS was not significantly different in comparison to each other. According to diagnosis, the 
Fig. 2 Annual proportion according to radiographic classification. a Central canal stenosis (CCS) classification; b facet joint degeneration (FJD) classification; c lateral recess stenosis (LRS) classification; d foraminal stenosis (FS) classification
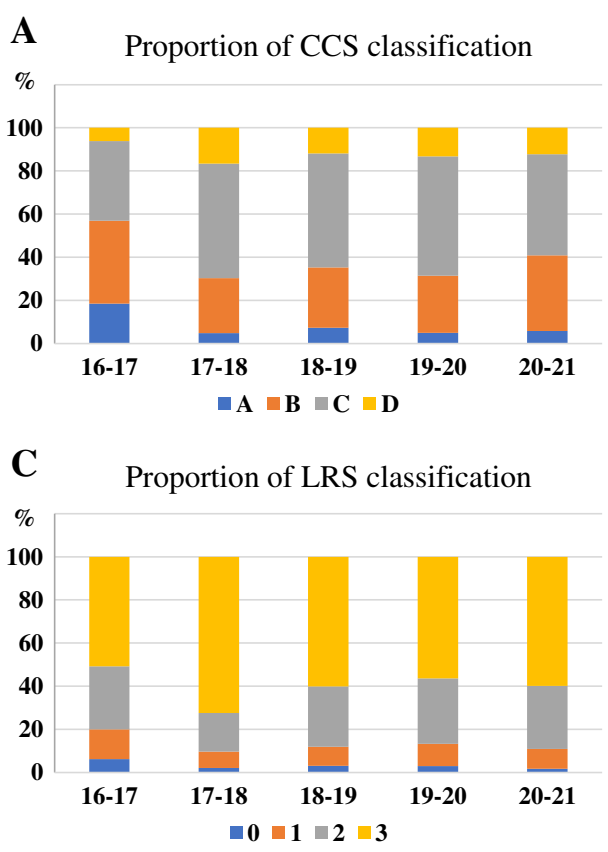

B Proportion of FJD classification

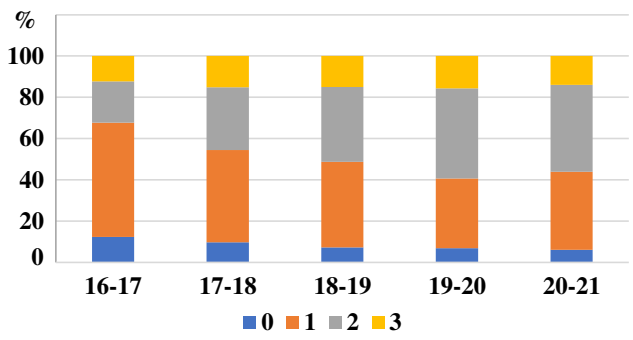

D Proportion of FS classification

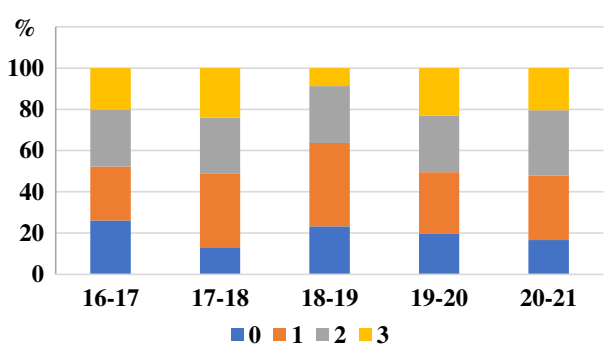

A

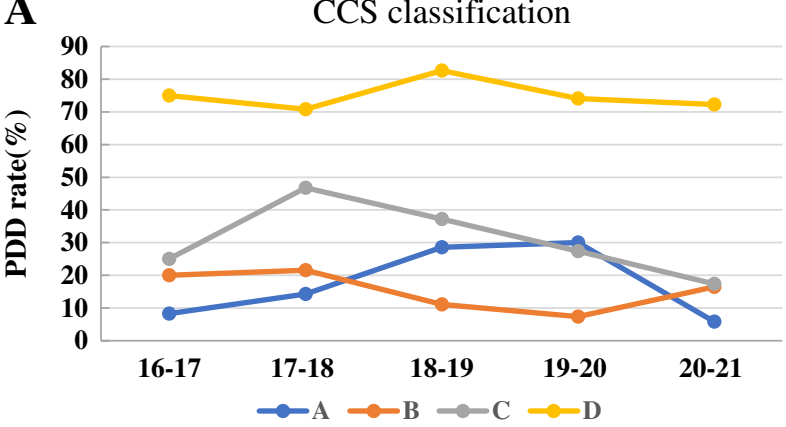

C

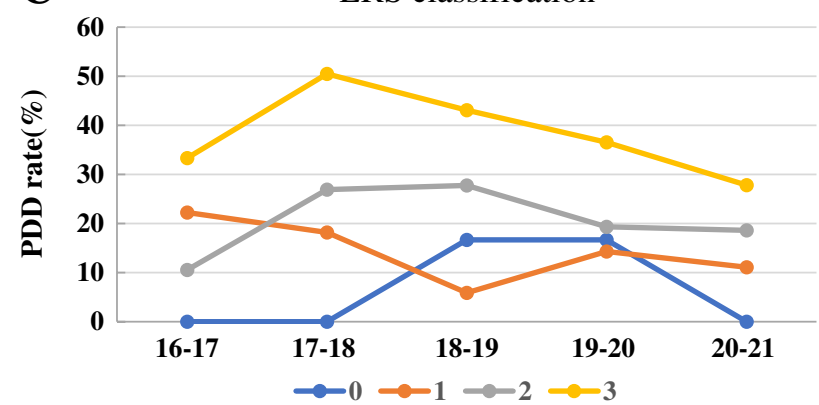

B

FJD classification

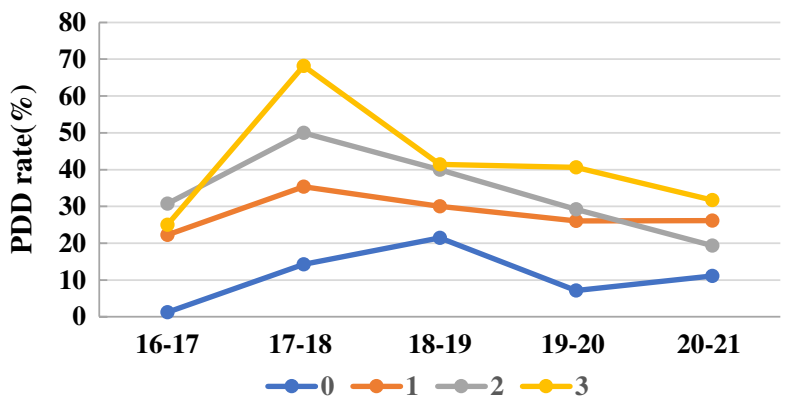

D

FS classification

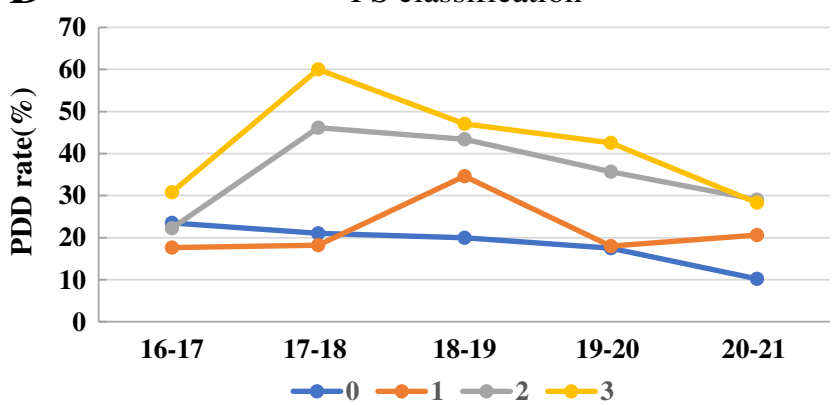

Fig. 3 Annual posterior direct decompression (PDD) rate according to radiographic classification. a Central canal stenosis (CCS) classification; b facet joint degeneration (FJD) classification; c lateral recess stenosis (LRS) classification; $\mathbf{d}$ foraminal stenosis (FS) classification

total PDD rate is $28.62 \%$ for LSS and $33.94 \%$ for LSS/spondylolisthesis $(p=0.12)$.

Univariate analysis showed year, CCS, FJD, LRS, and FS classification were all related with PDD, whereas sex, age, BMI, surgical segments, and spondylolisthesis were not. The PDD rate increased with the rise of all four parameter grade ( $p$ for trend $<0.05$ ). Their overall and annual multivariable logistic regressions are shown in Table 3. Considering the overall PDD rate for grade A and B CCS is $15.02 \%$ (50/333), grade D CCS is the utmost risk factor for PDD $(\mathrm{OR}=17.77, p<0.001)$. The annual OR values for grade $\mathrm{D}$ CCS had consistently been high in all 5 years. Considering 
Table 3 Multivariable logistic regression models for the associations between radiographic parameters and PDD

\begin{tabular}{|c|c|c|c|c|c|c|c|}
\hline & & $\begin{array}{l}\text { Total OR } \\
(95 \% \mathrm{CI})\end{array}$ & $\begin{array}{l}2016-2017 \\
\text { OR }(95 \% \mathrm{CI})\end{array}$ & $\begin{array}{l}2017-2018 \\
\text { OR }(95 \% \mathrm{CI})\end{array}$ & $\begin{array}{l}2018-2019 \\
\text { OR }(95 \% \mathrm{CI})\end{array}$ & $\begin{array}{l}2019-2020 \\
\text { OR }(95 \% \mathrm{CI})\end{array}$ & $\begin{array}{l}2020-2021 \\
\text { OR }(95 \% \mathrm{CI})\end{array}$ \\
\hline \multirow[t]{3}{*}{ CCS grade } & $\mathrm{A}-\mathrm{B}$ & Ref & Ref & Ref & Ref & Ref & Ref \\
\hline & $\mathrm{C}$ & $2.41(1.67,3.51)^{*}$ & $1.68(0.41,7.10)$ & $3.31(1.38,8.56)$ & $3.62(1.66,8.51)$ & $3.06(1.25,8.38)$ & $1.36(0.68,2.73)$ \\
\hline & $\mathrm{D}$ & $\begin{array}{c}17.77(10.54 \\
30.76)^{*}\end{array}$ & $\begin{array}{c}29.75(2.23 \\
894.99)^{*}\end{array}$ & $\begin{array}{c}6.47(1.95, \\
23.63)^{*}\end{array}$ & $\begin{array}{c}31.22(8.80 \\
137.58)^{*}\end{array}$ & $\begin{array}{c}43.71(12.36 \\
183.55)^{*}\end{array}$ & $\begin{array}{c}15.43(6.29 \\
40.92)^{*}\end{array}$ \\
\hline \multirow[t]{3}{*}{ FJD grade } & $0-1$ & Ref & Ref & Ref & Ref & Ref & Ref \\
\hline & 2 & $1.24(0.89,1.73)$ & $1.61(0.32,7.52)$ & $1.59(0.64,3.99)$ & $1.80(0.88,3.72)$ & $1.61(0.77,3.42)$ & $0.68(0.35,1.30)$ \\
\hline & 3 & $2.04(1.32,3.14)^{*}$ & $3.57(0.34,35.20)$ & $3.63(1.14,12.55)$ & $1.74(0.64,4.70)$ & $3.17(1.22,8.34)$ & $1.29(0.54,2.96)$ \\
\hline \multirow[t]{3}{*}{ LRS grade } & $0-1$ & Ref & Ref & Ref & Ref & Ref & Ref \\
\hline & 2 & $1.98(1.05,3.98)$ & $0.76(0.07,8.37)$ & $2.37(0.43,19.29)$ & $3.15(0.74,21.91)$ & $1.20(0.36,4.76)$ & $2.20(0.66,10.09)$ \\
\hline & 3 & $4.63(2.59,8.92)^{*}$ & $3.54(0.57,32.98)$ & $\begin{array}{c}7.58(1.75 \\
54.43)^{*}\end{array}$ & $\begin{array}{c}7.43(1.94, \\
49.05)^{*}\end{array}$ & $\begin{array}{c}3.44(1.18 \\
12.65)^{*}\end{array}$ & $3.96(1.29,17.38) *$ \\
\hline \multirow[t]{3}{*}{ FS grade } & $0-1$ & Ref & Ref & Ref & Ref & Ref & Ref \\
\hline & 2 & $1.92(1.36,2.70)^{*}$ & $1.68(0.33,8.45)$ & $1.71(0.69,4.26)$ & $2.04(1.00,4.19)$ & $3.20(1.45,7.26)^{*}$ & $1.99(1.04,3.83)^{*}$ \\
\hline & 3 & $2.42(1.64,3.55)^{*}$ & $2.75(0.46,17.03)$ & $2.66(1.06,6.91)^{*}$ & $2.58(0.83,8.09)$ & $\begin{array}{l}4.95(2.11, \\
12.02)^{*}\end{array}$ & $2.02(0.94,4.31)$ \\
\hline
\end{tabular}

$C C S$ central canal stenosis; FJD facet joint degeneration; $L R S$ lateral recess stenosis; $F S$ foraminal stenosis; OR (95\%CI) odds ratio (95\% confidence interval); Ref reference; *statistical significance, $p<0.05$

both the overall PDD rate for grades 0 and 1 of FJD, LSR, and FS is $25.87 \%$ (111/429), $11.93 \%$ (13/109), and $22.98 \%$ (108/470) and their overall OR values, we hypothesized that while they were all moderately increasing the risk of PDD, their effect on PDD is comparable.

\section{Discussion}

In the past four years after gaining further experience in LLIF surgery, our institution had observed a continuous decline in the annual staged surgery rates as well as annual PDD rates in grade 3 FJD, LRS, and FS, as well as grade C CCS segments. Despite this, the annual PDD rate for grade $\mathrm{D}$ remained at very high levels all through the 5 years $(70.88 \sim 82.61 \%)$. Logistic regression analysis had shown grade D CCS as the utmost risk factor for PDD $(\mathrm{OR}=17.77)$. And grade $3 \mathrm{LRS}(\mathrm{OR}=4.63)$, grade $3 \mathrm{FS}$ $(\mathrm{OR}=2.42)$, grade $\mathrm{C} \mathrm{CCS}(\mathrm{OR}=2.41)$, and grade $3 \mathrm{FJD}$ $(\mathrm{OR}=2.04)$ were also moderately correlated with PDD.

As an indirect decompression technique, many have concurred that severe CCS is a relative contradiction for LLIF $[1,2]$, and PDD is necessary for the presence of severe CCS. However, there are no clear definitions of severe CCS and no consensus on which degree of stenosis, where indirect decompression may not work. Several recent studies claimed that LLIF successfully achieves indirect decompression in patients with extremely severe CCS (Grade D) [9, 10, 28]. Shimizu et al. [9] reported that LLIF without PDD provided successful clinical outcomes for grade D patients at one year of follow-up, which is partly attributed to the resolution of pathological spinal instability. Likewise, Walker et al. [10] reported that LLIF may successfully achieve indirect decompression in grade D patients, if they have spondylolisthesis and a collapsed disc height. However, this study shows that the annual PDD rate for grade D CCS still remained at very high levels in the five years. Multivariate analysis showed grade D CCS as the utmost risk factor for PDD with the greatest OR value, which is consistent all throughout the five years of this study. In a radiographic comparative study [29], the mean central canal area (CCA) of grade D segments immediately after LLIF was $49.87 \pm 18.81 \mathrm{~mm}^{2}$, which was significantly smaller than the mean pre-operative CCA of grade $\mathrm{C}$ segments $\left(82.06 \pm 26.97 \mathrm{~mm}^{2}\right)$. Considering the indirect decompression mechanism of LLIF and the uncertainty of long-term clinical outcomes of LLIF for grade D, we recommend PDD for grade D patients. LLIF may also show success in selected grade D patients, who we are yet to accurately recognize based on our current knowledge.

Grade C segment accounts for 50.38\% (454/901) of all our surgical segments. There is a continuous decline in the annual PDD rate for grade $\mathrm{C}$ segments in the past 4 years. In the last 12 months, only $17.39 \%$ of grade $\mathrm{C}$ segments needed PDD, which is not significantly different from grade B. Compared with the overall PDD rate of both grades A and $\mathrm{B}$, the overall and the last year OR values of grade $\mathrm{C}$ were $2.41(p<0.05)$ and $1.36(p=0.39)$ respectively. Shimizu et al. [28] found that in the instance of severe stenosis, the mean CCA improved from $54.5 \mathrm{~mm}^{2}$ pre-operatively to 84.7 $\mathrm{mm}^{2}$ at three weeks post-operation, and to $132.6 \mathrm{~mm}^{2}$ at the last follow-up, an average 28.3 months later. Takahashi et al. [30] found that in spondylolisthesis patients with severe CCS 
$\left(\mathrm{CCA} \leq 50 \mathrm{~mm}^{2}\right)$, the mean CCA improved from $35.8 \mathrm{~mm}^{2}$ pre-operatively to $81.4 \mathrm{~mm}^{2}$ immediately after surgery, and to $105.7 \mathrm{~mm}^{2}$ at two years post-operatively. Indirect decompression produces immediate positive results that continued to improve over time as observed with the ligamentum flavum cross-sectional area and disc bulging both shrinking significantly [31]. Therefore, with this analysis, we can consider grade $\mathrm{C}$ stenosis as a proper indication for LLIF with low PDD risk.

Given that severe FJD may prevent distraction of the neural foramen during graft insertion, it has been originally considered as relative contraindications for $\operatorname{LLIF}[19,20]$. In our study, compared with the overall PDD rate of both grades 0 and 1 FJD, grade 3 FJD only moderately increased the risk of $\mathrm{PDD}(\mathrm{OR}=2.10, p=0.001)$. Its $\mathrm{OR}$ value is only $1.29(p=0.56)$ in the most recent year. A study conducted by Navarro-Ramirez et al. [32] had found FJD and facet tropism were not associated with restoration of disc height, foraminal area, and CCA after LLIF, but instead, their study revealed significant clinical improvements were observed for LLIF patients with the presence of locked facets. Another study [33] claimed that the presence of metabolically active arthropathy had no significant effect on the amount of indirect decompression obtained with LLIF surgery. In fact, their data trends towards greater indirect decompression with degenerative facets. Our own study showed, with regard to the average change values of disc height, both sides foraminal height, canal diameter, and CCA, grade 3 FJD showed no significant differences compared with that of the other grades (data not published), unless it is completely fused. Thus, we consider severe FJD as a moderate risk factor for PDD.

This study showed that the overall OR value of grade 3 LRS is $4.83(p=0.04)$, compared with that of both grade 0 and 1 LRS. Narrowing of the lateral recess can cause radicular pain and/or low back pain. The diameter of the lateral recess increased bilaterally after LLIF [20]. Severe facet hypertrophy, synovial cysts, and osteophytes arising from the posterior endplates were reported as risk factors for lateral recess indirect decompression failure [20, 34]. While bony LRS may represent a risk factor for failure of indirect decompression [13, 16], we consider that LRS caused by soft tissue elements is not. MRI could not differentiate bony or non-bony LRS and grade 3 LRS segments account for $60.49 \%$ (545/901) of all segments; hence, we do not regularly see grade 3 LRS as a risk factor for PDD.

Indirect decompression via LLIF had shown to achieve great radiographic outcomes similar to direct approaches in terms of relieving FS [34]. In a prospective study, the foraminal area increased by $24.7 \%$ and the foraminal height by $13.5 \%$ after LLIF [20]. In a prospective randomized study [3], LLIF results in an increased foraminal area by $23 \%$ compared with $4.9 \%$ in MIS-TLIF on the approach side at three month follow-up. Kirnaz et al. [35] recommended indirect decompression for patients who have symptomatic FS as long as we can confirm the source of the pain by eliciting radicular symptoms with a Kemp's test. However, at present, there has been no research that looks at the efficacy of LLIF for patients only with radiculopathy. Likewise, radiculopathy that prevailed over neurogenic claudication is not a good indication for LLIF in our institution. In our study, grade 3 FS moderately increases the risk of PDD $(\mathrm{OR}=2.42, p<0.001)$.

Our study had several limitations and can be identified as follows. Firstly, this was a retrospective study by nature. Secondly, the classification of CCS, LRS, and FS was based on MRI, which could not differentiate bony stenosis or soft tissue stenosis and could not fully distinguish the pathological features of stenosis. Thirdly, intra-operative and post-operative factors were not analyzed in the current study. Lastly, the current study does not involve symptom evaluations which in hindsight could have skewed some parts of our data. There is increasing evidence shown to pre-operative clinical symptoms as the main indicator of successful indirect decompression. Khalsa et al. [36] reported that pre-operative assessment of rest pain level in the supine position has a significant association with reduction in leg and back sores in patients undergoing indirect decompression. Two studies $[19,37]$ claimed that patients with radicular symptoms unimproved with flexion may require direct decompression, and it is proposed that if patients are able to achieve dynamic symptom relief in a sitting or lying position, they may benefit from LLIF without requiring direct decompression, which is consistent with our experience.

In conclusion, grade 3 FJD, LRS, and FS, as well as grade C CCS, moderately increase the risk of PDD, which means there are proper indications for LLIF with low PDD risk. Extreme severe CCS (grade D) is the greatest determinant to perform the PDD procedure after LLIF. We would regularly recommend PDD for grade D segments.

Acknowledgements The authors thank Dr. Meng-ling Tang for her useful assistance in statistical analysis. We thank Deanna Chin for editing this manuscript.

Author contribution FL and QC made a substantial contribution to the study design, data analysis, and interpretation. JL, TZ, and NZ made a substantial contribution to the data collection. JL made a substantial contribution towards writing up the manuscript. All authors have read and approved the final manuscript.

Funding This work is supported by the National Natural Science Foundation of China (81702225) and the Major Scientific and Technological Plan for Medicine and Health of Zhejiang Province (WKJ-ZJ-1903).

Availability of data and materials The data will be available upon request. 


\section{Declarations}

Ethical approval This study was performed in line with the principles of the Declaration of Helsinki. Approval was obtained from the ethics committee of the Second Affiliated Hospital, School of Medicine, Zhejiang University (2021-1058).

Consent to participate Written informed consent was exempted for this study.

Consent for publication All authors listed have approved this manuscript to be published.

Competing interests The authors declare no competing interests.

Open Access This article is licensed under a Creative Commons Attribution 4.0 International License, which permits use, sharing, adaptation, distribution and reproduction in any medium or format, as long as you give appropriate credit to the original author(s) and the source, provide a link to the Creative Commons licence, and indicate if changes were made. The images or other third party material in this article are included in the article's Creative Commons licence, unless indicated otherwise in a credit line to the material. If material is not included in the article's Creative Commons licence and your intended use is not permitted by statutory regulation or exceeds the permitted use, you will need to obtain permission directly from the copyright holder. To view a copy of this licence, visit http://creativecommons.org/licenses/by/4.0/.

\section{References}

1. McAfee PC, Regan JJ, Geis WP, Fedder IL (1998) Minimally invasive anterior retroperitoneal approach to the lumbar spine. Emphasis on the lateral BAK. Spine 23(13):1476-1484. https:// doi.org/10.1097/00007632-199807010-00009

2. Ozgur BM, Aryan HE, Pimenta L, Taylor WR (2006) Extreme lateral interbody fusion (XLIF): a novel surgical technique for anterior lumbar interbody fusion. Spine J 6(4):435-443. https:// doi.org/10.1016/j.spinee.2005.08.012

3. Isaacs RE, Sembrano JN, Tohmeh AG (2016) Two-year comparative outcomes of MIS lateral and MIS transforaminal interbody fusion in the treatment of degenerative spondylolisthesis: part II: radiographic findings. Spine 41 Suppl 8:S133-S144. https://doi. org/10.1097/BRS.0000000000001472

4. Lin GX, Akbary K, Kotheeranurak V, Quillo-Olvera J, Jo HJ, Yang XW et al (2018) Clinical and radiologic outcomes of direct versus indirect decompression with lumbar interbody fusion: a matched-pair comparison analysis. World Neurosurg 119:e898e909. https://doi.org/10.1016/j.wneu.2018.08.003

5. Pawar AY, Hughes AP, Sama AA, Girardi FP, Lebl DR, Cammisa FP (2015) A comparative study of lateral lumbar interbody fusion and posterior lumbar interbody fusion in degenerative lumbar spondylolisthesis. Asian Spine J 9(5):668-674. https://doi.org/ 10.4184/asj.2015.9.5.668

6. Sembrano JN, Tohmeh A, Isaacs R (2016) Two-year comparative outcomes of MIS lateral and MIS transforaminal interbody fusion in the treatment of degenerative spondylolisthesis: part I: clinical findings. Spine 41 Suppl 8:S123-S132. https://doi.org/10.1097/ BRS.0000000000001471

7. Tan MWP, Sayampanathan AA, Jiang L, Guo CM (2020) Comparison of outcomes between single-level lateral lumbar interbody fusion and transforaminal lumbar interbody fusion: a metaanalysis and systematic review. Clin Spine Surg 34(10):395-405. https://doi.org/10.1097/BSD.0000000000001107
8. Jang HD, Lee JC, Seo JH, Roh YH, Choi SW, Shin BJ (2021) Comparison of Minimally invasive LLIF, minimally invasive TLIF, and open PLIF in the treatment of single-level spondylolisthesis of L4-L5. World Neurosurg S1878-8750(21):0156101568. https://doi.org/10.1016/j.wneu.2021.10.064

9. Shimizu T, Fujibayashi S, Otsuki B, Murata K, Matsuda S (2021) Indirect decompression via oblique lateral interbody fusion for severe degenerative lumbar spinal stenosis: a comparative study with direct decompression transforaminal/posterior lumbar interbody fusion. Spine J 21(6):963-971. https://doi.org/10.1016/j. spinee.2021.01.025

10. Walker CT, Xu DS, Cole TS, Alhilali LM, Godzik J, Angel Estrada $S$ et al (2021) Predictors of indirect neural decompression in minimally invasive transpsoas lateral lumbar interbody fusion. J Neurosurg Spine:1-11. https://doi.org/10.3171/2020.8. SPINE20676

11. Nakashima H, Kanemura T, Satake K, Ishikawa Y, Ouchida J, Segi $\mathrm{N}$ et al (2019) Unplanned second-stage decompression for neurological deterioration caused by central canal stenosis after indirect lumbar decompression surgery. Asian Spine J:584-91. https://doi.org/10.31616/asj.2018.0232

12. Ozgur BM, Aryan HE, Pimenta L, Taylor WR. Extreme lateral interbody fusion (XLIF): a novel surgical technique for anterior lumbar interbody fusion. Spine J 6(4):435-43. https://doi.org/10. 1016/j.spinee.2005.08.012

13. Wang TY, Nayar G, Brown CR, Pimenta L, Karikari IO, Isaacs RE (2017) Bony lateral recess stenosis and other radiographic predictors of failed indirect decompression via extreme lateral interbody fusion: multi-institutional analysis of 101 consecutive spinal levels. World Neurosurg 106:819-826. https://doi.org/10. 1016/j.wneu.2017.07.045

14 Fujibayashi S, Hynes RA, Otsuki B, Kimura H, Takemoto M, Matsuda S (2015) Effect of indirect neural decompression through oblique lateral interbody fusion for degenerative lumbar disease. Spine 40(3):E175-82. https://doi.org/10.1097/BRS.0000000000 000703

15. Tempel ZJ, McDowell MM, Panczykowski DM, Gandhoke GS, Hamilton DK, Okonkwo DO et al (2018) Graft subsidence as a predictor of revision surgery following stand-alone lateral lumbar interbody fusion. J Neurosurg Spine 28(1):50-56. https://doi.org/ 10.3171/2017.5.SPINE16427

16 Malham GM, Parker RM, Goss B, Blecher CM (2015) Clinical results and limitations of indirect decompression in spinal stenosis with laterally implanted interbody cages: results from a prospective cohort study. Eur Spine J 24 Suppl 3:339-45. https://doi.org/ 10.1007/s00586-015-3807-3

17 Morgan CD, Walker CT, Godzik J, Ohiorhenuan IE, Catapano JS, Hemphill C et al (2021) When indirect decompression fails: a review of 220 consecutive direct lateral interbody fusions and unplanned secondary decompression. Spine 46(16):1081-6. https://doi.org/10.1097/BRS.0000000000003976

18. Malham GM, Ellis NJ, Parker RM, Blecher CM, White R, Goss $\mathrm{B}$ et al (2017) Maintenance of segmental lordosis and disk height in stand-alone and instrumented extreme lateral interbody fusion (XLIF). Clin Spine Surg 30(2):E90-E98. https://doi.org/10.1097/ BSD.0b013e3182aa4c94

19. Nemani VM, Aichmair A, Taher F, Lebl DR, Hughes AP, Sama AA et al (2014) Rate of revision surgery after stand-alone lateral lumbar interbody fusion for lumbar spinal stenosis. Spine 39(5):E326-E331. https://doi.org/10.1097/BRS.0000000000 000141

20. Oliveira L, Marchi L, Coutinho E, Pimenta L (2010) A radiographic assessment of the ability of the extreme lateral interbody fusion procedure to indirectly decompress the neural elements. Spine 35(26 Suppl):S331-S337. https://doi.org/10.1097/BRS. 0b013e $3182022 \mathrm{db} 0$ 
21 Khajavi K, Shen A, Hutchison A (2015) Substantial clinical benefit of minimally invasive lateral interbody fusion for degenerative spondylolisthesis. Eur Spine J 24 Suppl 3:314-21. https://doi.org/ 10.1007/s00586-015-3841-1

22. Kim SJ, Lee YS, Kim YB, Park SW, Hung VT (2014) Clinical and radiological outcomes of a new cage for direct lateral lumbar interbody fusion. Korean J Spine 11(3):145-151. https://doi.org/ 10.14245/kjs.2014.11.3.145

23. Park D, Mummaneni PV, Mehra R, Kwon Y, Kim S, Ruan HB et al (2020) Predictors of the need for laminectomy after indirect decompression via initial anterior or lateral lumbar interbody fusion. J Neurosurg Spine:1-7. https://doi.org/10.3171/2019.11. SPINE19314

24. Schizas C, Theumann N, Burn A, Tansey R, Wardlaw D, Smith FW et al (2010) Qualitative grading of severity of lumbar spinal stenosis based on the morphology of the dural sac on magnetic resonance images. Spine 35(21):1919-1924. https://doi.org/10. 1097/BRS.0b013e3181d359bd

25. Bartynski WS, Lin L (2003) Lumbar root compression in the lateral recess: MR imaging, conventional myelography, and CT myelography comparison with surgical confirmation. AJNR Am J Neuroradiol 24(3):348-360

26. Lee S, Lee JW, Yeom JS, Kim KJ, Kim HJ, Chung SK et al (2010) A practical MRI grading system for lumbar foraminal stenosis. AJR Am J Roentgenol 194(4):1095-1098. https://doi.org/10.2214/ AJR.09.2772

27. Pathria M, Sartoris DJ, Resnick D (1987) Osteoarthritis of the facet joints: accuracy of oblique radiographic assessment. Radiology 164(1):227-230. https://doi.org/10.1148/radiology.164.1. 3588910

28. Shimizu T, Fujibayashi S, Otsuki B, Murata K, Matsuda S (2020) Indirect decompression with lateral interbody fusion for severe degenerative lumbar spinal stenosis: minimum 1-year MRI followup. J Neurosurg Spine:1-8. https://doi.org/10.3171/2020.1.SPINE 191412

29. Li J, Li H, Zhang N, Wang ZW, Zhao TF, Chen LW et al (2020) Radiographic and clinical outcome of lateral lumbar interbody fusion for extreme lumbar spinal stenosis of Schizas grade D: a retrospective study. BMC Musculoskelet Disord 21(1):259. https://doi.org/10.1186/s12891-020-03282-6

30. Takahashi Y, Funao H, Yoshida K, Sasao Y, Nishiyama M, Isogai N et al (2021) Sequential MRI changes after lateral lumbar interbody fusion in spondylolisthesis with mild and severe lumbar spinal stenosis. World Neurosurg 152:e289-e296. https://doi.org/ 10.1016/j.wneu.2021.05.093

31. Nakashima H, Kanemura T, Satake K, Ishikawa Y, Ouchida J, Segi N et al (2019) Indirect decompression on MRI chronologically progresses after immediate postlateral lumbar interbody fusion: the results from a minimum of 2 years follow-up. Spine 44(24):E1411-E8. https://doi.org/10.1097/BRS.0000000000 003180

32. Navarro-Ramirez R, Lang G, Moriguchi Y, Elowitz E, Corredor JA, Avila MJ et al (2017) Are locked facets a contraindication for extreme lateral interbody fusion? World Neurosurg 100:607-618. https://doi.org/10.1016/j.wneu.2016.11.059

33. Malham GM, Parker RM, Goss B, Blecher CM, Ballok ZE (2014) Indirect foraminal decompression is independent of metabolically active facet arthropathy in extreme lateral interbody fusion. Spine 39(22):E1303-E1310. https://doi.org/10.1097/BRS.0000000000 000551

34. Lang G, Perrech M, Navarro-Ramirez R, Hussain I, Pennicooke B, Maryam F et al (2017) Potential and limitations of neural decompression in extreme lateral interbody fusion-a systematic review. World Neurosurg 101:99-113. https://doi.org/10.1016/j.wneu. 2017.01.080

35. Kirnaz S, Navarro-Ramirez R, Gu J, Wipplinger C, Hussain I, Adjei J et al (2020) Indirect decompression failure after lateral lumbar interbody fusion-reported failures and predictive factors: systematic review. Global Spine J 10(2 Suppl):8S-16S. https://doi. org/10.1177/2192568219876244

36. Khalsa AS, Eghbali A, Eastlack RK, Tran S, Akbarnia BA, Ledesma JB et al (2019) Resting pain level as a preoperative predictor of success with indirect decompression for lumbar spinal stenosis: a pilot study. Global Spine J 9(2):150-154. https://doi. org/10.1177/2192568218765986

37. Lim KZ, Daly C, Brown J, Goldschlager T (2019) Dynamic posture-related preoperative pain as a single clinical criterion in patient selection for extreme lateral interbody fusion without direct decompression. Global Spine J 9(6):575-82. https://doi.org/ $10.1177 / 2192568218811317$

Publisher's note Springer Nature remains neutral with regard to jurisdictional claims in published maps and institutional affiliations. 